\title{
Notochord repression of endodermal Sonic hedgahog permits pancreas development
}

\author{
Matthias Hebrok, ${ }^{1}$ Seung K. Kim, ${ }^{1}$ and Douglas A. Melton ${ }^{2}$ \\ Department of Molecular and Cellular Biology and Howard Hughes Medical Institute, Harvard University, \\ Cambridge, Massachusetts 02138 USA
}

\begin{abstract}
Notochord signals to the endoderm are required for development of the chick dorsal pancreas. Sonic hedgehog (SHH) is normal ly absent from pancreatic endoderm, and we provide evidence that notochord, in contrast to its effects on adjacent neuroectoderm where SHH expression is induced, represses SHH expression in adjacent nascent pancreatic endodem. We identify activin- $\beta B$ and FGF2 as notochord factors that can repress endodermal SHH and thereby permit expression of pancreas genes including Pdx1 and insulin. Endoderm treatment with antibodies that block hedgehog activity also results in pancreatic gene expression. Prevention of SHH expression in prepancreatic dorsal endoderm by intercellular signals, like activin and FGF, may be critical for permitting early steps of chick pancreatic development.
\end{abstract}

[Key Words: Pancreas; endoderm; chicken; fibroblast growth factor; activins; hedgehog]

Received February 5, 1998; revised version accepted April 2, 1998.

Signals between endoderm and mesoderm govern the identity and patterning of vertebrate respiratory and digestive organs including the trachea, lungs, stomach, intestines, and pancreas (Golosow and Grobstein 1962; Wessels and Cohen 1967; Haffen et al. 1989; Bellusci et al. 1997). At least two distinct endoderm-mesoderm interactions are necessary for devel opment of the pancreas. Early signals from the notochord to the endoderm permit dorsal pancreatic morphogenesis, and initiate and maintain expression of genes required for pancreas development (Kim et al. 1997a,b), including the homeodomain transcription factors PDX 1 and ISL1 (Jonsson et al. 1994; Ahlgren et al. 1996, 1997; Offield et al. 1996). Later signals from the mesenchyme to the endoderm permit subsequent development of both dorsal and ventral pancreatic buds, which later fuse (Golosow and Grobstein 1962; Le Douarin and Bussonnet 1966; Wessels and Cohen 1967; Dieterlen-Lièvre 1970). Despite various efforts, the signaling molecules involved in pancreatic cell interactions have not been identified (for review, see Slack 1995).

Expression of Sonic hedgehog (Shh), a potent intercelIular patterning signal, is strikingly absent from pancreatic endoderm, in contrast to uniform endodermal Shh expression in the anlagen of organs rostral or caudal to the pancreas (Ahlgren et al. 1997; A pelqvist et al. 1997; Kim et al. 1997b). Ectopic SHH expression results in ab-

\footnotetext{
${ }^{1}$ These authors contributed equally to this work.

${ }^{2}$ Corresponding author.

E-MAIL dmelton @biohp.harvard.edu; FAX (617) 495-8557.
}

normal morphogenesi s and gene expression in lungs (BelIusci et al. 1997), neural tube (Echelard et al. 1993; Pourquié et al. 1993; Ericson et al. 1995), and limb buds (Masuya et al. 1995; Riddle et al. 1995) demonstrating the importance of limiting Shh expression in these organs. Ectopic SHH expression in the mouse pancreas during the later epithelial-mesenchymal signaling does not affect endocrine or exocrine cytodifferentiation, but does prevent proper morphogenesis (Apelqvist et al. 1997). This suggests that late maintenance of Shh repression is crucial for normal pancreas morphogenesis. Here we ask whether early cell interactions necessary to initiate pancreatic development depend on repression of Shh expression in endoderm.

In this study we investigate the early role of notochord signals in patterning chick pancreatic endoderm. The re sults suggest a simple model in which notochord signals prevent Shh expression in foregut endoderm, thereby permitting pancreatic development. Grafting experiments demonstrate that notochord can repress endodermal Shh. N otochord removal before completion of notochord-endoderm signaling results in ectopic Shh expression in the pancreatic anlage, abnormal morphogenesis, and prevents gene expression required for endocrine and exocrine differentiation. We further show that two signaling factors expressed in notochord during pancreas specification, activin- $\beta B$ and fibroblast growth factor 2 (FGF2), repress endodermal Shh and induce expression of pancreatic genes including $\mathrm{Pdx} 1$ and insulin. Inhibition of $\mathrm{SHH}$ in isolated prepancreatic endoderm with an antibody that neutralizes Hedgehog activity is also sufficient to induce pancreatic gene expression. Thus, in con- 
trast to neural and somitic induction that require $\mathrm{SHH}$ from notochord, pancreatic endodermal differentiation is inhibited by $\mathrm{SHH}$, and requires notochord signals to prevent $\mathrm{SHH}$ activity in endoderm.

\section{Results}

Shh expression is absent in pancreatic endoderm

In situ hybridization of stage-11 (13 somites) chicks reveals uniform Shh expression in columnar epithelium of the prechordal foregut, the extreme rostral limit of definitive endoderm (Fig. 1A). Floor plate expression of Shh is evident, and notochord is absent at this rostral level. Ventral foregut cells in the stomach/duodenal anlage at stage 11 have a columnar shape and express Shh (Fig. 1B). Dorsal foregut epithelial cells adjacent to notochord, however, have a thinner squamous cuboidal shape and do not express detectable Shh. In contrast, expression of Shh in endoderm caudal to the anterior intestinal portal, including the pancreatic, midgut, and hindgut anlagen (Fig. 1C), appears as two ventrolateral stripes separated by midline endoderm, which does not express Shh. Endoderm in this region has a squamous morphology until later stages when the notochord and dorsal endoderm separate and the endoderm, covered by mesenchyme, assumes a columnar shape (Fig. 1D-F). Thus, patterns of gut epithelial cell shape and Shh expression correlate with proximity of the notochord to the epithelial cell layer (Fig. 1; upper schematic). Early endodermal Shh expression in mice (Echelard et al. 1993; Bitgood and McMahon 1995; Apelqvist et al. 1997) was known to vary al ong the rostrocaudal axis, but previous studies did
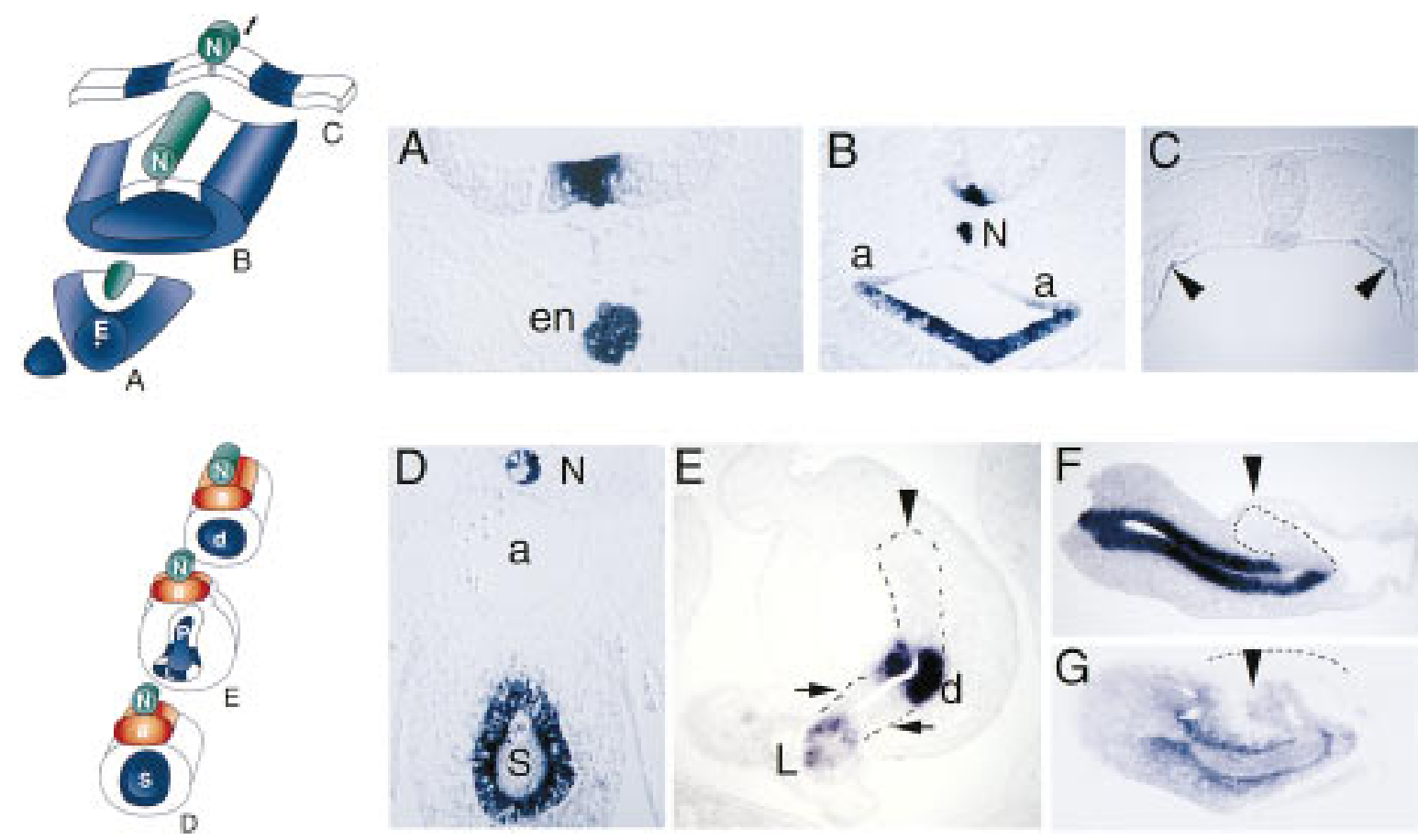

Figure 1. Patterns of Shh and Ptc expression in endoderm and pancreas. Upper schematic shows transverse sections through gut endoderm (E) and adjacent tissues including notochord (N) at stage 11 (A-C). Endoderm without Shh expression is white, endoderm with Shh expression is blue. Lower schematic shows transverse sections through notochord (N), aorta (a), stomach (S), pancreas (P), and duodenal (d) endoderm and adjacent mesenchyme at stage 18-19 (D-G). (A) In situ hybridization with Shh probe of transverse section through prechordal endoderm at the extreme rostral end of the digestive tract. Shh expression in the floor plate of the neural tube is detected dorsal to endodermal (en) cells al so expressing Shh. N ote absence of notochord at this rostrocaudal level. (B) Shh expression in foregut endoderm rostral to the anterior intestinal portal. Shh expression is evident in floor plate cells and notochord ( $N$ ), dorsal to endoderm expression. N ote absence of dorsal endodermal Shh expression and the transition from columnar shape of ventral endodermal cells to squamous shape of dorsal midline endoderm. Paired dorsal aortas are marked "a". (C) M idgut/hindgut Shh expression. A rrowheads point to two stripes of endodermal Shh expression. Endoderm medial and lateral to these Shh-expressing cells does not express detectable Shh. Floor plate and regressing Hensen's node cells at this caudal level do not express detectable Shh at this stage. (D) Shh expression in stomach (S) endoderm and notochord (N) after aortas (a) fuse. Expression of Shh is evident in dorsal and ventral columnar epithelial cells. (E) Endodermal Shh expression in the pancreatic anlage. Endoderm in the nascent dorsal (arrowhead) and two ventral pancreatic buds (arrows) does not express Shh in contrast to strong expression in duodenal (d) endoderm between the buds and ventral common bile duct endoderm in the liver (L). (F) Sagittal section of dissected foregut revealing Shh expression anterior to the dorsal pancreas bud (arrowhead and dotted outline) in stomach and duodenal endoderm. Space adjacent to the dorsal pancreas bud is the lumen of the right omphalomesenteric vein. (G) Sagittal section revealing foregut expression of Ptc in mesenchyme adjacent to stomach and duodenal endoderm and in dorsal pancreas endoderm (arrowhead), but little detectable Ptc in dorsal pancreas mesenchyme (outlined by dashed line). (A-G) Dorsal is at the top. $(F, G)$ Anterior is at left. 
not correlate notochord-endoderm proximity with endodermal patterns of cell shape and Shh expression.

By stage 15 (25 somites), midline fusion of the paired dorsal aortas separates the notochord from the foregut (Fig. 1, bottom schematic). The chick pancreas derives from a dorsal and paired ventral endodermal evaginations that express PdxI and Isl 1 (Kim et al. 1997b), and later fuse. At stage 15 and in later stages, Shh is expressed uniformly in enteric endoderm rostral (Fig. 1D) and caudal to the pancreas but is absent from the dorsal and ventral pancreatic endoderm in chicks (Fig. 1E). In mice, which also have dorsal and ventral pancreatic buds, pancreatic Shh expression is similar to that in chicks at later stages (A hlgren et al. 1997; Kim et al. 1997b).

Expression of patched (Ptc), a receptor for Shh (Goodrich et al. 1996; Marigo et al. 1996), is also similar in chicks and mice. Ptc transcription is induced by $\mathrm{SHH}$; thus, high levels of Ptc expression indicate abundant $\mathrm{SHH}$. Endodermal $\mathrm{SHH}$ in the gut, including stomach and duodenum (Fig. 1F), is flanked by high levels of Ptc expression in adjacent mesenchyme (Fig. 1G). We detect very little Ptc expression in mesenchyme adjacent to pancreatic endoderm, however, consistent with absence of Shh in pancreatic endoderm (Fig. 1F). Endodermal Ptc expression is also evident in the pancreatic anlage (Fig. 1G, arrow; compare staining of darker dorsal bud endoderm to lighter surrounding dorsal mesenchyme outlined by dashes).

\section{Notochord signals repress endodermal Shh expression}

Our observations on Shh and Ptc gene expression in endoderm suggest that signals from the notochord downregulate adjacent endodermal Shh expression. A series of notochord deletion and grafting experiments provide strong evidence for such a notochord-endoderm interaction in chicks (Fig. 2). Eighteen hours after deletion of notochord adjacent to foregut endoderm, ectopic Shh expression is observed in squamous dorsal epithelial cells (Fig. 2A); fate mapping studies (Matsushita 1996) indicate that this region of foregut includes the pancreatic anlage. We do not observe a squamous to columnar shape transition in dorsal endodermal cells until later stages when they contact mesenchyme. Grafting an ectopic notochord adjacent to ventral foregut results in down-regulation of Shh in adjacent epithelium, and a reproducible change in cell morphology from columnar to cuboidal (Fig. 2B), reminiscent of notochord-induced changes in neuroectodermal cell shape (Schoenwolf and Smith 1990). In contrast, control grafts of somites adjacent to ventral foregut epithelium do not affect Shh expression or cell shape (Fig. 2C). N otochord deletion (Kim et al. 1997a) or ectopic notochord grafts do not affect adjacent endodermal expression of HNF3 $\beta$ (Fig. 2D), demonstrating that notochord signals may regulate expression of a specific subset of endodermal genes, including Shh.

Two days after notochord del etion, we observe ectopic expression of Shh and Ptc in a rudimentary dorsal pan-

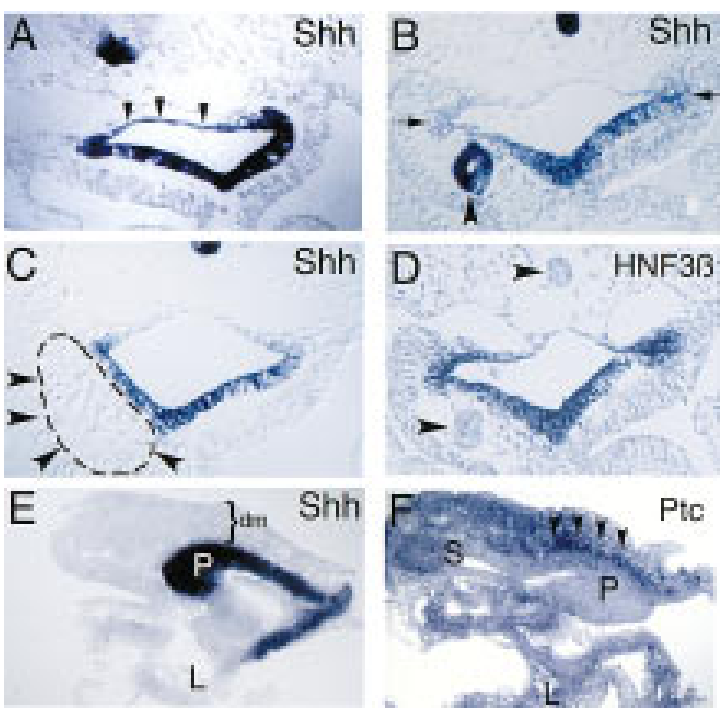

Figure 2. N otochord signals repress Shh expression in adjacent endoderm. Transverse sections through foregut adjacent to the anterior intestinal portal at stage 16 (A-D). (A) Ectopic Shh expression in dorsal foregut endoderm after notochord deletion $(n=10)$ at stage $10-11$. Arrowheads outline blue dorsal endoderm. Contrast to Fig. 1B. (B) Ectopic notochord graft decreases adjacent endodermal Shh expression; compare to contralateral control side (arrows). Ectopic notochord al so expresses Shh (arrowhead). The endoderm adjacent to notochord grafts is reproducibly thinner than corresponding control endoderm on the contralateral side $(n=18)$ The apparent lumen in the transplanted notochord is an artifact of histologic preparation. (C) Endodermal Shh expression after insertion of the ninth somite (dashed line and arrowheads), from a stage 10 donor, adjacent to endoderm. Shh expression in endoderm is unaffected compared to the contral ateral side $(n=4)$. (D) HNF3 $\beta$ expression in foregut endoderm after notochord grafting. Endogenous or grafted notochord (arrowheads) does not express HNF3 $\beta$ at this stage. Ventral endodermal HNF3 $\beta$ expression is unaffected by ectopic notochord. (E,F) Sagittal sections through dissected pancreatic anlage and adjacent anterior foregut at stage 19. (E) Ectopic endodermal Shh expression in the dorsal pancreas bud $(P)$ after notochord deletion at stage 11 . Some liver $(L)$ is seen in this section but liver and stomach endoderm are out of the section plane. Mesenchyme $(\mathrm{dm})$ overlying the dorsal pancreas bud is indicated. (F) shows stomach (S), liver (L), and ectopic Ptc expression in mesenchyme (arrowheads) adjacent to the dorsal pancreas bud $(\mathrm{P})$ after notochord deletion. Dorsal is toward the top; anterior is toward the left in $\mathrm{E}$ and $\mathrm{F}$.

creatic evagination (Fig. 2E,F), which subsequently fails to devel op (Kim et al. 1997a). These results demonstrate that notochord signals prevent initial Shh and Ptc expression in the dorsal pancreatic anlage.

N otochord factors activin and FGF initiate pancreatic differentiation

An in vitro endoderm culture method (Kim et al. 1997a) provides an assay for factors that can initiate expression of pancreas genes, including Pdxl and insulin, in isolated pancreatic endoderm. As shown in Figure 3, midline endoderm and notochord in the pancreatic anlage can be 
dissected free from adjacent tissues including somites, aortic endothelium, and splanchnic mesoderm. When first isolated, this endoderm does not express detectable Shh, insulin, or Pdx1 (Fig. 3D, column E0). Previously (Kim et al. 1997a), we have also shown that notochord can be isolated without adherent endoderm and that notochord cultured al one does not express insulin or Pdx1. After 3 days of growth in vitro, isolated endoderm does not express $\mathrm{Pdx} 1$ or insulin, but now does express Shh (Fig. 3D, column E) and Ptc (see below). This shows that separation of pancreatic endoderm from notochord allows endodermal Shh expression, which in turn correlates with a lack of $\mathrm{Pdx} 1$ and insulin expression. Growth of isolated notochord with endoderm results in expression of both $\mathrm{Pdx}$ l and insulin (Fig. 3D, column $E+N$ ). Thus, even in the presence of notochord-derived $\mathrm{SHH}$, notochord signals can stimulate endodermal pancreas gene expression (see Discussion).

A ctivin- $\beta B$, a member of the transforming growth factor- $\beta$ (T GF- $\beta$ ) family, has been shown to repress Shh expression in Hensen's node during establishment of avian left-right axial asymmetry (Levin et al. 1995, 1997). In stage- $12^{-}$chicks, activin- $\beta$ B expression is detectable in notochord tissue but not in more lateral mesoderm (Fig. 4A), confirming previous work (Connolly et al. 1995). Activin- $\beta A$ expression is not detected at this stage (Connolly et al. 1995; data not shown). We tested activin- $\beta B$ for activity in our pancreatic endoderm assay (Fig. 4B) and found that activin- $\beta B$ induced $P d x 1$ and low levels of insulin expression. At higher concentrations, activin stimulated increased levels of Pdxl and insulin expres- sion. No activity was detected in similar experiments with TGF- $\beta 1$, BMP-4, chordin, or activin at $0.1 \mathrm{U} / \mathrm{ml}$ (data not shown).

Activin-loaded beads inserted adjacent to Hensen's node have been shown to repress Shh expression (Levin et al. 1995). As shown in Figure 5, beads loaded with activin- $\beta B$ and inserted adjacent to the endoderm cell layer decrease endodermal Shh expression. This suggests that activin-like signals may represent part of the notochord signal that regulates endodermal Shh.

This model of activin function predicts that endodermal transcription of $\mathrm{Pdx} 1$ and insulin resulting from activin- $\beta \mathrm{B}$ signal ing would be inhibited by addition of $\mathrm{SHH}$ protein. Indeed, we find that addition of increasing concentrations of purified bioactive $\mathrm{SHH}$ amino-terminal peptide (Martí et al. 1995) with activin- $\beta B$ to endoderm suppresses expression of endodermal insulin and $\mathrm{Pdx} 1$ (see Fig. 4C). Inhibition by $\mathrm{SHH}$ is concentration dependent between 1 to $40 \mu \mathrm{g} / \mathrm{ml}$, an in vitro activity range similar to that previously shown for $\mathrm{SHH}$ activity on motor neuron induction in neural tissue (Martí et al. 1995).

Concentrations of FGF2 $>50 \mathrm{ng} / \mathrm{ml}$ repress expression of XIhbox8 in Xenopus endoderm (Gamer and Wright 1995). FGF2 is expressed in notochord and lateral mesoderm of stage-12- chicks (see Fig. 4A) as well as in endoderm and adjacent tissues (Borja et al. 1993, 1996). Concentrations of FGF2 $\varangle 0.1 \mathrm{ng} / \mathrm{ml}$ have no detectable activity (data not shown). When added at a concentration of $1 \mathrm{ng} / \mathrm{ml}$ to pancreatic endoderm, FGF2 induces expression of $\mathrm{Pdxl}$ and insulin (see Fig. 4B), while suppress-
Figure 3. Separation of pancreatic endoderm and notochord promotes Shh expression and prevents $\mathrm{Pdx} 1$ and insulin expression. (A) Schematic transverse section through stage 12 pancreatic anlage summarizing tissue-restricted expression patterns of Gnotl (notochord), caudal (endoderm), GATA5 (endothelial and splanchnic mesoderm), GMHox (splanchnic mesoderm), and Pax1 (ventral somitic mesoderm), adapted from Patten and Carlson (1974). (B) Gene expression detected by RT-PCR in dorsal pancreatic endoderm isolated at stage 12 . Total RNA was harvested and analyzed by RTPCR for caudal, GNot1, GATA5, GMHox, Pax1, HNF3 $\beta$, and $\beta$-tubulin RN As in whole torso (WT), which includes ectoderm, mesoderm, and endoderm germ layers, freshly dissected midline endoderm (E0) or notochord ( $N$ ). $\beta$-Tubulin was used as a loading control. No signal was detected in control samples of RNA from whole embryo trunk samples untreated with reverse transcriptase $(-R T)$. (C) Schematic of in vitro pancreatic endoderm growth and RT-PCR analysis reveal ing pancreas marker gene induction by notochord. Endoderm and notochord were removed from stage-12 embryos as previously described (Kim et al. 1997a) and grown in contact in a collagen matrix. (D) RT-PCR analysis of RN A from freshly dissected endoderm (EO) shows no insulin, Pdx1, or Shh expression. Endoderm isolated from stage-12 embryos and grown for 3 days in vitro (E) without notochord expresses Shh but not insulin or Pdx1. Recombination and growth of endoderm with notochord (E+N) results in insulin and $\mathrm{Pdx1}$ expression. High levels of Shh expression by notochord in the E+N sample are also detected.

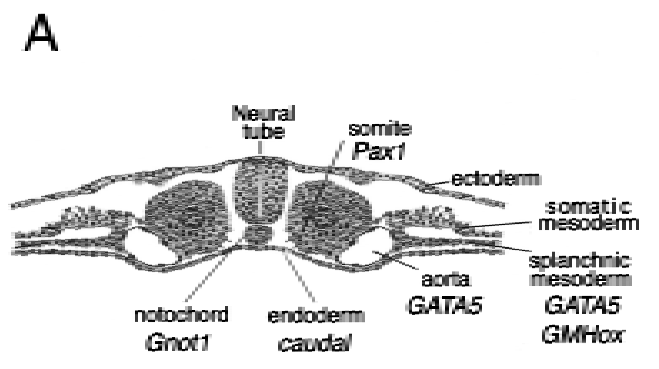

B

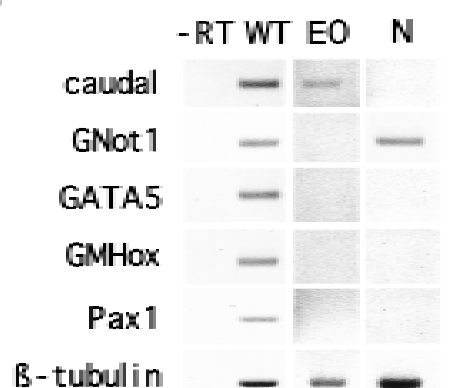

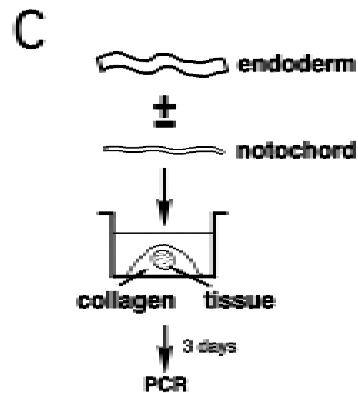

D

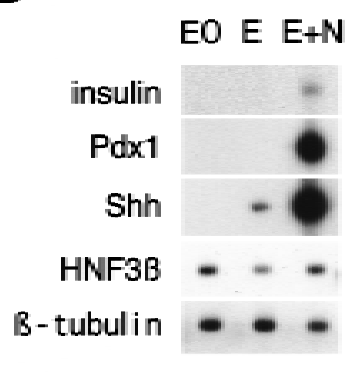




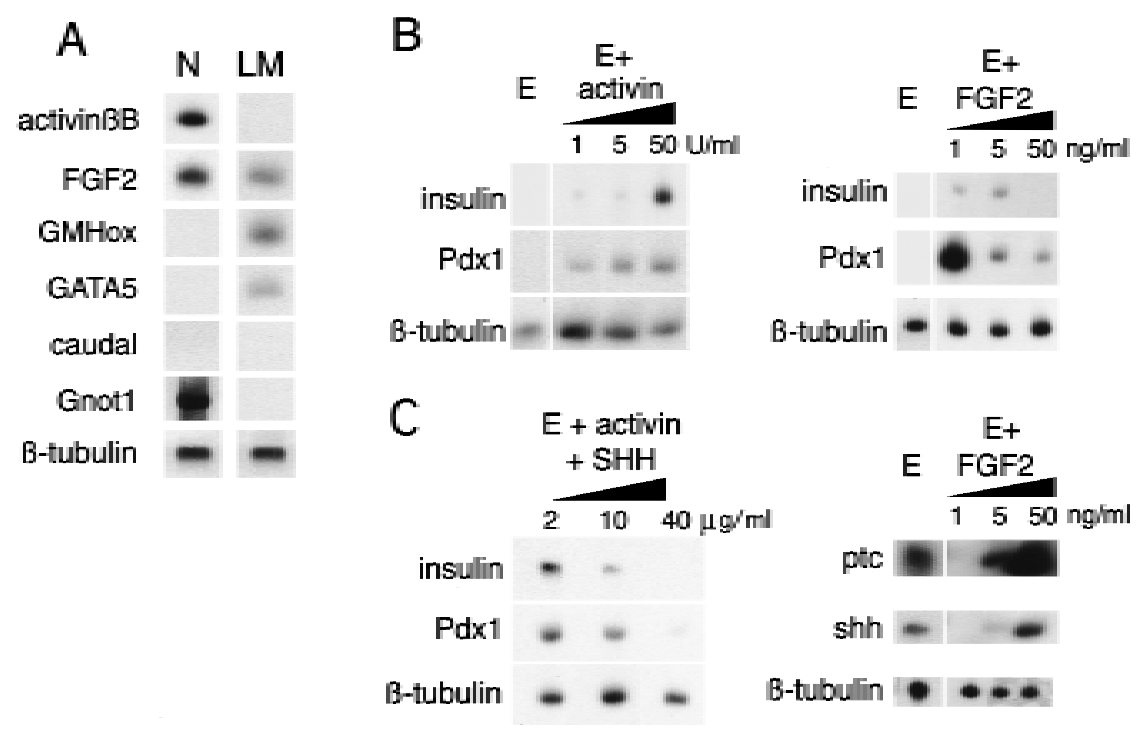

Figure 4. Activin- $\beta B$ and FGF2 mimic notochord activity in inducing pancreatic genes. (A) N otochord ( $\mathrm{N}$ ) isolated at stage 12 expresses FGF2, activin- $\beta B$, and Gnot1 assayed by RT-PCR. Absent GMHox or GATA5 signals indicate lack of adherent lateral mesoderm. Absence of adherent midline endoderm is demonstrated by lack of detectable caudal expression. Isolated lateral mesoderm (LM) expresses FGF2, GMHox, and GATA5, but not activin- $\beta$ B, caudal or Gnot1. $\beta$-Tubulin was used as a loading control. (B) Endoderm isolated at stage 12 was grown in the absence $(E)$ or presence of increasing amounts of activin$\beta B$ (Etactivin) or recombinant FGF2 (E+FGF2), then analyzed by RT-PCR for expression of insulin, Pdx1, or $\beta$-tubulin. (C) Isolated stage 12 endoderm grown in the presence of $5 \mathrm{U} / \mathrm{ml}$ human activin- $\beta \mathrm{B}$ and recombinant Shh at increasing doses,or grown in the presence of FGF2 at increasing doses. Endoderm grown in activin and Shh was assayed for expression of insulin, Pdx1, and $\beta$-tubulin; explants grown in FGF2 were tested for expression of patched (ptc), Sonic hedgehog (shh) and $\beta$-tubulin. PCR products of $\beta$-tubulin transcripts were used as loading controls.

ing endodermal expression of Shh and Ptc (see Fig. 4C). In contrast, FGF2 at higher concentrations $(10-50 \mathrm{ng} / \mathrm{ml})$ reduces $\mathrm{Pdx} 1$ and insulin expression, while increasing transcription of Shh and Ptc (see Fig. 4B,C). High concentrations of FGF2 also inhibit the stimulatory effects of activin- $\beta B$ on endodermal $\mathrm{Pdx} 1$ and insulin expression (data not shown).

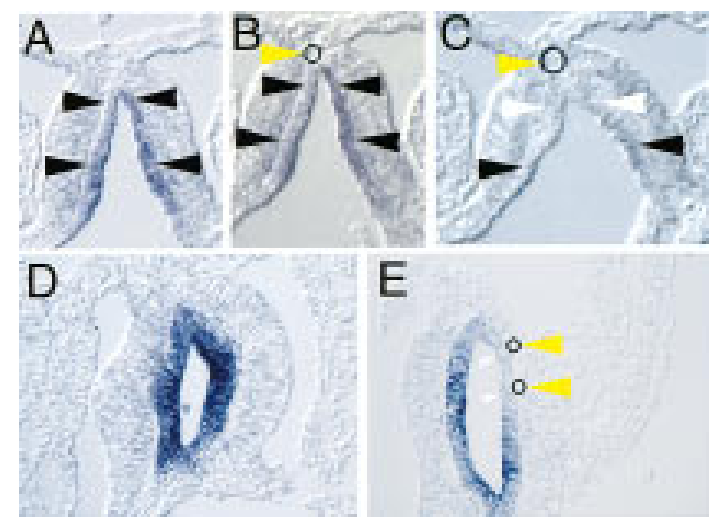

Figure 5. Ectopic activin down-regulates endodermal Shh. Black arrowheads indicate wild-type endogenous expression of endodermal Shh. White arrowheads indicate where expression is not present in embryos adjacent to ectopic activin-coated beads; yellow arrowheads and black circles indicate beads. (A-E) In situ hybridization with Shh probe at stage 17-18, (A-C) at the level of midgut and $(D, E)$ in the stomach anlage. Control bead (B) soaked in phosphate buffered sal ine or activin-soaked beads $(C, E)$ were implanted adjacent to midline foregut endoderm in stage 10 embryos. Shh expression in unmanipulated endoderm $(A, D)$ is the same as in the embryos with control bead implants. In $E$, the beads became detached during processing for in situ hybridization.
Inhibition of endodermal Shh signaling initiates pancreas gene expression

To test whether prevention of SHH signaling in pancreatic endoderm is sufficient to initiate pancreatic differentiation, we performed antibody blocking experiments with an affinity-purified antibody (M artí et al. 1995) previously shown to prevent notochord-derived SHH induction of motor neurons in neuroectoderm. Isolated pancreatic endoderm incubated with $\mathrm{SHH}$ antibody expresses Pdx1 and insulin at levels similar to those induced in endoderm by notochord (Fig. 6). Exposure of pancreatic endoderm to an antibody agai nst carboxypeptidase $A$ or preimmune serum does not result in PdxI or insulin expression. These results indicate that one mechanism for initiating pancreatic differentiation in endoderm is to suppress endodermal $\mathrm{SHH}$ activity.

\section{Discussion}

Dorsal pancreas development in the chick requires interactions (Kim et al . 1997a) between the pancreatic endoderm and the notochord, an established source of signaling molecules including $\mathrm{SHH}$. SH H from notochord induces expression of Shh in overlying neuroectodermal fl oor plate cells (Echelard et al. 1993); thus, we were surprised to find that notochord signals repress Shh expression in endoderm, thereby permitting pancreas devel opment. Results in this paper provide an explanation for this apparent paradox; besides $\mathrm{SH} \mathrm{H}$, notochord expresses activin- $\beta B$ and FGF2, two factors that can repress endodermal Shh expression. Thesefindings may reconcile the seemingly opposite responses of endoderm and ectoderm to notochord signals and further emphasize that pancreatic endoderm and neuroectoderm (Sherman et al. 1993; 


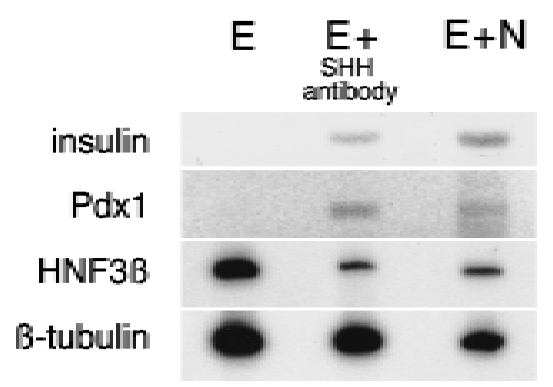

Figure 6. Antibody-mediated induction of pancreatic gene expression by endoderm. Explanted stage 12 endoderm was grown al one (E), in contact with nickel-agarose beads preincubated in an affinity-purified antiserum specific to the 19-kD amino-terminal Shh peptide ( $\mathrm{E}+\mathrm{SHH}$ antibody) or in contact with stage 12 notochord $(E+N)$. Samples were collected after 3 days and analyzed by RT-PCR for expression of insulin, Pdx1, HNF3 $\beta$, and $\beta$-tubulin.

Dono and Zeller 1994; Liem et al. 1995, 1997) are simiIarly patterned by integration of activin, $\mathrm{SHH}$, and FGF signaling pathways.

Ventral pancreatic endoderm is not contacted by notochord and previously we have shown that notochord removal does not affect gene expression in the ventral pancreatic anlage (Kim et al . 1997a). The dorsal pancreas in chicks develops larger, insulin-secreting islets than the ventral pancreas, which develops mainly into exocrine acinar tissue mixed with smaller, glucagon-secreting islets (Beaupain and Dieterlen-Lièvre 1974). Although our conclusions are limited to development of the dorsal pancreas in chicks, two results described in this work suggest that mechanisms that initiate dorsal and ventral pancreas development are similar. First, ventral pancreatic endoderm, like dorsal endoderm, does not express Shh, suggesting that there must be mechanisms that initiate and maintain Shh repression in ventral, as well as dorsal pancreatic endoderm. Second, ectopic notochord grafts adjacent to ventral endoderm decrease endodermal Shh expression, demonstrating that the ventral endoderm is competent to transduce intercel lul ar signals that lead to Shh repression. Tissues adjacent to ventral pancreatic endoderm include ventrolateral splanchnic mesoderm and vascular endothelium and currently we are studying their effects on initial repression of ventral endodermal Shh.

The possible role of activin and FGF in specification of pancreatic endoderm

Several lines of evidence from previous work suggested activin- $\beta B$ as a candidate for a notochord factor that permits pancreas differentiation. Activin- $\beta B$ was shown to be expressed in notochord when prepancreatic endoderm requires notochord signals (Connolly et al . 1995). Studies on endoderm differentiation in Xenopus suggested that activin and mature Vgl, a related (TGF- $\beta$ ) factor, could induce endodermal expression of XIHbox8 (Gamer and Wright 1995; Henry et al. 1996). Activin has also been shown to induce insulin expression by islet cells (Y asuda et al. 1993). Lastly, activin- $\beta B$ had been shown to repress Shh expression in Hensen's node during establishment of avian left-right axial asymmetry (Levin et al. 1995, 1997). Our results show that activin- $\beta$ B can decrease Shh expression, while inducing expression of $\mathrm{Pdx} 1$ and insulin by chick endoderm.

BMP-4, TGF- $\beta 1$, and chordin lack activity in our assays, and activin- $\beta A$ expression between stages 2 and 20 of chick embryogenesis has not been detected (Thomsen et al . 1990; Connolly et al. 1995; S. Kim and M. Hebrok, unpubl.). Expression of cVgl, the chick homolog of Vgl, has been demonstrated in somitic mesoderm but is absent in notochord until stage 14 (Sel eiro et al. 1996; Shah et al. 1997), and we have not yet detected an effect of somites on endoderm (Fig. 2C). Thus, our studies identify activin- $\beta B$ as a possible candidate signal from notochord that induces pancreatic endoderm differentiation and make it unlikely that activin- $\beta A, c V g l, B M P-4$, TGF- $\beta 1$, or chordin account for this notochord activity. Our studies, however, cannot yet establish activin- $\beta B$ as an endogenous initiating signal of pancreatic endoderm development.

In contrast to activin- $\beta$ B expression, which is restricted to the axial midline, at least four isoforms of FGF2 generated by alternate splicing have been detected in mesodermal structures including notochord, as well as in neural tube, endoderm, and endothelium (Borja et al. 1993, 1996). FGF2 has been shown to repress XIH box8 expression in Xenopus vegetal endodermal explants (Gamer and Wright 1995) at concentrations $>50 \mathrm{ng} / \mathrm{ml}$. Separate studies of limb bud development have established a role for FGF2 or FGF4 in the apical ectodermal ridge, where FGF functions both to maintain Shh expression and to promote competence to $\mathrm{SHH}$ activity in underlying limb bud mesenchyme (Riley et al . 1993; Fallon et al. 1994; Laufer et al. 1994; N iswander et al. 1994). We have shown that FGF2 regulates endodermal gene expression in a concentration-dependent manner. Thus, similar to activin- $\beta B$, FGF2 may govern pancreas differentiation by regulating levels of endodermal $\mathrm{SHH}$. In combination, these activin and FGF-like activities may be sufficient to offset potentially inhibitory input from notochord SHH (Figs. 3D, column E+N , and 4C). Further studies are required to determine whether FGF2 is an endogenous notochord signal that initiates pancreatic endoderm differentiation.

\section{Shh and pancreas development}

We have correl ated effects of FGF2 on Pdx1 and insulin expression in chick endoderm with FGF2 effects on Shh and Ptc. Similarly, we have shown that addition of purified $\mathrm{SHH}$ inhibits induction of endodermal Pdxl and Shh expression by activin- $\beta$ B. In contrast, antibody inhibition of endodermal $\mathrm{SHH}$ activity is sufficient to allow pancreatic gene expression. Thus, mechanisms that restrict Shh expression in endoderm appear to be critical for initial pancreatic development. We have shown that misexpression of Shh in pancreatic endoderm after no- 
tochord del etion results in absence of further pancreatic differentiation (Kim et al. 1997a) and correl ates with increased mesenchymal Ptc expression and a thickened dorsal pancreatic mesenchymal layer. Misexpression of $\mathrm{SHH}$ in embryonic lung endoderm (Bellusci et al. 1997) also results in hypercellular mesenchyme, increased mesenchymal Ptc expression, and decreased endodermal branching.

Recently A pelqvist et al. (1997) showed that pancreatic misexpression of Shh from a Pdxl promoter in otherwise wild-type mice resulted in abnormal pancreas morphogenesis, ectopic intestinal smooth muscle, and an absent spleen. However, endocrine and exocrine cell differentiation was detectable in these mice. We observe a more severe, essentially apancreatic phenotype from ectopic dorsal pancreatic Shh expression after notochord deletion (Kim et al. 1997a). These differences may arise because notochord deletion results in both early ectopic endodermal Shh expression and lack of endodermal Pdx1 expression. Thus, both initial repression of endodermal Shh expression (results presented here) and maintenance of Shh repression after notochord-endoderm separation (A pelqvist et al. 1997) are necessary for pancreatic cytodifferentiation and morphogenesis. Absence of Shh in dorsal endoderm along most of the rostral-caudal axis in early vertebrate development, however, indicates that Shh repression is not sufficient for pancreatic development outside the pancreatic anlage.

\section{A cell interaction model of pancreas development}

Our results suggest that cell interactions between notochord and endoderm govern chick pancreas development. We have shown that members of the TGF- $\beta$ and FGF families, which are expressed in notochord, can stimulate responses in dorsal endoderm that prevent Shh expression. Lack of endodermal Shh permits mesenchymal (and possibly endodermal) Ptc function, resulting in expression of genes encoding transcription factors including Pdx1, Isl 1, and Pax6; thus, notochord-endoderm interactions can affect subsequent mesenchymal-epithelial interactions. These transcription factors are critical for later cell differentiation (A hlgren et al. 1996, 1997; Sander et al. 1997; St.-Onge et al . 1997) and expression of the genes necessary for normal pancreas function, including glucagon, insulin, and digestive enzymes like carboxypeptidase A and amylase. Furthermore, our results suggest that cell interactions can also repress Shh in ventral pancreatic endoderm.

The results presented here and previously (Kim et al. 1997a) suggest that the endoderm is prepatterned and notochord factors act as permissive signals during initiati on of pancreas development. The activity of cell signals that permit dorsal pancreas development may be refined by local stimulatory and inhibitory activities. These include inhibitory (high) levels of FGF expressed in surrounding mesoderm, as well as $\mathrm{SHH}$ from adjacent notochord, floor plate, and lateral endoderm. Other factors including follistatin (Connolly et al. 1995; M iralles et al. 1998) may modulate the response to activin, and extra- cellular matrix components like heparan (Handler et al. 1997) may augment the activity of FGF. Localized expression of receptors or other signal transduction components of activin, FGF, and SHH may account for the observation that rostral, but not caudal, endoderm responds to notochord signals by expressing pancreas genes (Kim et al. 1997a). After the notochord separates from the endoderm, mechanisms must maintain Shh repression in the pancreas (A pelqvist et al. 1997). It will be interesting to study whether epithelial-mesenchymal interactions participate in the maintenance of pancreatic Shh repression. Mutations affecting Shh/Ptc, activin, and FGF signaling in mice exist and will allow us to test whether regulatory cell interactions in chicks described here are conserved during mammal ian pancreas development.

\section{Materials and methods}

Dissection, grafting, and in vitro endoderm growth methods

Methods for chick embryo growth, pancreas dissection and notochord removal, and in vitro growth of pancreatic endoderm are described in Kim et al. (1997a). Embryos were staged according to Hamburger and Hamilton (1951). Ectopic tissue, including notochord or the penultimate somite from stage 10-11 donor embryos, or protein-loaded nickel-agarose beads (Quiagen, Inc.) were inserted under an endoderm flap created by a rostrocaudal incision made lateral to the dorsal aorta in the recipient embryo (Sundin and Eichele 1992). After recovery at room temperature for 45-60 min, manipulated embryos were grown in vitro at $38^{\circ} \mathrm{C}$ for $\sim 18 \mathrm{hr}$ to stage 16 . By this stage, manipulated lateral endoderm has folded over and forms the ventral floor of the closing gut tube (Rosenquist 1971; M atsushita et al. 1996).

In situ hybridization, histochemistry, and RT-PCR

In situ hybridizations using Shh (Riddle et al. 1995) and Ptc ( $M$ arigo et al. 1996) sense and antisense probes were performed as described by Henry et al. (1996). M icroscopy and photography were performed as previously described (Kim et al. 1997a). RT-PCR and electrophoretic analysis of PCR products was performed as described (Wilson and Melton 1994; Kim et al. 1997a). Primer sequences used for chick $\beta$-tubulin, HNF-3 $\beta$, Pdx1, and insulin have been described (Kim et al. 1997a). Other primer sequences are listed forward then reverse, 5' to 3': Gnot1 (Knezevic et al. 1995), GCAAGAGTTCCTCAAGCAGCAGTAC and AAAGCTCAACCTCCACTGTGTCC; caudal (Frumkin et al. 1994), TGGACCATCCTGAGGAGGTTTTG and CCAGCTATCCATCATCTTGTGCC; GATA5 (Laverriere et al. 1994), CTAACTGCCACACAACCAACACC and TCGTAATGGAAGAAGGGGAGTTC; GMHox (Kuratani et al. 1994), CAAATCCTACTCAGGGGATGTGAC and TGACTGTGGGCACTTGATTCCTC; Shh (Riddle et al. 1995), TGGAGGATATGAAGGGAAGA and CTGAGTTTTCTGCTTTGACG; PtC (Marigo et al. 1996), TACATTGGGCTTCGTCATTGGCTCC and CAATCAGGATAACCACAGGCACTG; Paxl (Ebensperger et al. 1995), ATTCGACCGTGCGACATCAG and ATGTGCTTGACCACGTTGGG; FGF2 (Borja et al. 1993), GGCACTTCAAGGACCCCAAG and AAAGGATAGCTTTCTGTCCAGGTC; activin- $\beta B$ (GenBank accesssion no. Z71594; Connolly et al. 1995), GAACTTGGATGTTCAATGTGAGGG and GCAGTCTGTGCTTTTGCCTGAG. 
Endoderm assays with growth factors

Recombinant human FGF1, FGF2, FGF7, and porcine TGF- $\beta 1$ were from $R \& D$ Systems Inc. Activin $A$ and $B$ were provided by K. Symes (Boston University, MA) and A. Schneyer (M assachusetts General Hospital, Boston), and murine activin A was obtained as described (Sokol et al. 1990). Mouse BMP4 was obtained by transfection of COS cells (Basler et al. 1993) provided by K. Liem, Jr. and T. Jessell (both of Columbia U niversity, N ew York, NY). Purified 19-kD amino-terminal SHH and affinitypurified SHH antiserum AB 80 were provided by E. Martí (Instituto Cajal de N eurobiol ogia, M adrid, Spain) and A. M CM ahon (Harvard University, Cambridge, MA). Xenopus chordin was provided by E. De Robertis (UCLA). Pancreatic endoderm was grown in vitro, in collagen, and in serum-free medium (Kim et al. 1997a) supplemented with the appropriate growth factor. $\mathrm{Nickel-agarose}$ beads were soaked in $\mathrm{SHH}$ antiserum as described (Martí et al. 1995) for $1 \mathrm{hr}$ at room temperature, then wrapped with endoderm (notochordside contacting the bead) before embedding in collagen matrix. Control beads were soaked in PBS, preimmune serum, or undiluted polyclonal antiserum against carboxypeptidase A (Biogenesis).

\section{Acknowledgments}

We thank members of the M elton laboratory and Mary Dickinson, Andrew M cM ahon, Andrew Dudley, and Elizabeth Robertson for hel pful discussions. We are grateful to Karen Symes and A.L. Schneyer for providing activin, A. M CM ahon and E. M artí for SHH and $\mathrm{SHH}$ antiserum, Cliff Tabin for numerous DNA probes including pHH-2 and chicken Patched, E. De Robertis for Chordin, and K. Liem Jr. and T.M. Jessell for BM P4. We thank G. Chen and Q. Wu for excellent technical assistance. Wethank Renate Hellmiss for the schematic in Figure 1. This work was supported by a Howard Hughes M edical Institute (H HMI) postdoctoral fellowship to M.H. and a H HMI physician postdoctoral research fellowship to S.K.K. D.A.M. is an investigator of the HHMI.

The publication costs of this article were defrayed in part by payment of page charges. This article must therefore be hereby marked "advertisement" in accordance with 18 USC section 1734 solely to indicate this fact.

\section{References}

Ahlgren, U., J. Jonsson, and H. Edlund. 1996. The morphogenesis of the pancreatic mesenchyme is uncoupled from that of the pancreatic epithelium in IPF1/PDX1-deficient mice. Development 122: 1409-1416.

A hlgren, U., S.L. Pfaff, T.M. Jessell, T. Edlund, and H. Edlund. 1997. Independent requirement for ISLI in formation of pancreatic mesenchyme and islet cells. Nature 385: 257-260.

A pel qvist, Å., U. A hlgren, and H. Edlund. 1997. Sonic hedgehog directs special ised mesoderm differentiation in the intestine and pancreas. Curr. Biol. 7: 801-804.

Basler, K., T. Edlund, T.M. Jessell, and T. Yamada. 1993. Control of cell pattern in the neural tube: Regulation of cell differentiation by dorsalin-1, a novel TGF $\beta$ family member. Cell 73: 687-702.

Beaupain, D. and F. Dieterlen-Lièvre. 1974. Etude immunocytologique de la differenciation du pancreas endocrine chez I'embryon de poulet. II. Glucagon. Gen. Comp. Endocrinol. 23: 421-423.

Bellusci, S., Y. Furuta, M.G. Rush, R. Henderson, G. Winnier, and B.L.M. Hogan. 1997. Involvement of Sonic hedgehog
(Shh) in mouse embryonic lung growth and morphogenesis. Development 124: 53-63.

Bitgood, M.J. and A.P. MCM ahon. 1995. Hedgehog and BMP genes are coexpressed at many diverse sites of cell-cell interaction in the mouse embryo. Dev. Biol. 172: 126-138.

Borja, A.Z.M., C. Meijers, and R. Zeller. 1993. Expression of alternatively spliced bFGF first coding exons and antisense mRN As during chicken embryogenesis. Dev. Biol. 157: 110118.

Borja, A.Z.M., C. Murphy, and R. Zeller. 1996. alt FGF-2, a novel ER-associated FGF-2 protein isoform: Its embryonic distribution and functional analysis during neural tube development. Dev. Biol. 180: 680-692.

Connolly, D., K. Patel, E. Seleiro, D. Wilkinson, and J. Cooke. 1995. Cloning, sequencing and expressional analysis of the chick homologue of follistatin. Dev. Genet. 17: 65-77.

Dieterlen-Lièvre, F. 1970. Tissus exocrine et endocrine du pancreas chez l'embryon de poulet: Origine et interactions tissulaires dans la differenciation. Dev. Biol. 22: 138-156.

Dono, R. and R. Zeller. 1994. Cell-type-specific nuclear translocation of fibroblast growth factor-2 isoforms during chicken kidney and limb morphogenesis. Dev. Biol. 163: 316-330.

Ebensperger, C., J. Wilting, B. Brand-Saberi, Y. Mizutani, B. Christ, R. Balling, and H. Koseki. 1995. Pax-1, a regulator of sclerotome development is induced by notochord and floor plate signals in avian embryos. Anat. Embryol. 191: 297310.

Echelard, Y., D.J. Epstein, B. St.-Jacques, L. Shen, J. M ohler, J.A. McMahon, and A.P. McMahon. 1993. Sonic hedgehog, a member of a family of putative signalling molecules, is implicated in the regulation of the CN S polarity. Cell 75: 14171430.

Ericson, J., J. Muhr, M. Placzek, T. Lints, T.M. Jessell, and T. Edlund. 1995. Sonic hedgehog induces the differentiation of ventral forebrain neurons: A common signal for ventral patterning within the neural tube. Cell 81: 747-756.

Fallon, J.F., A. Lopez, M.A. Ros, M.P. Savage, B.B. Olwin, and B.K. Simandl. 1994. FGF-2: A pical ectodermal ridge growth signal for chick limb development. Science 264: 104-107.

Frumkin, A., G. Pillemer, R. Haffner, N. Tarcic, Y. Gruenbaum, and A. Faisod. 1994. A role for CdxA in gut closure and intestinal epithelia differentiation. Development 120: 253263.

Gamer, L.W. and C.V.E. Wright. 1995. Autonomous endodermal determination in Xenopus: Regulation of expression of the pancreatic gene XIH box 8. Dev. Biol. 171: 240-251.

Golosow, N. and C. Grobstein. 1962. Epitheliomesenchymal interaction in pancreatic morphogenesis. Dev. Biol. 4: 242255.

Goodrich, L.V., R.L. Johnson, L. Milenkovic, J.A. McMahon, and M.P. Scott. 1996. Conservation of the hedgehog/ patched signaling pathway from flies to mice: Induction of a mouse patched gene by hedgehog. Genes \& Dev. 10: 301312.

Haffen, K., M. Kedinger, and P.M. Simon-Assmann. 1989. Cell contact dependent regulation of enterocytic differentiation. In Human gastrointestinal development (ed. E. Lebenthal), pp. 19-39. Raven Press, N ew York, NY.

Hamburger, V. and H.L. Hamilton. 1951. A series of normal stages in the development of the chick embryo. J. Exp. Morph. 88: 49-92.

Handler, M., P.D. Yurchenco, and R.V. Iozzo. 1997. Developmental expression of perlecan during murine embryogenesis. Dev. Dyn. 210: 130-145.

Henry, G.L., I.H. Brivanlou, D.S. Kessler, A. Hemmati-Brivan- 
Iou, and D.A. Melton. 1996. TGF- $\beta$ signals and a prepattern in Xenopus laevis endodermal development. Development 122: 1007-1015.

Jonsson, J., L. Carlsson, T. Edlund, and H. Edlund. 1994. Insulinpromoter-factor 1 is required for pancreas development in mice. Nature 371: 606-609.

Kim, S.K., M. Hebrok, and D.A. Melton. 1997a. N otochord to endoderm signaling is required for pancreas development. Devel opment 124: 4243-4252.

_-_. 1997b. Pancreas devel opment in the chick embryo. Cold Spring Harbor Symp. Quant. Biol. 62: 377-383.

Knezevic, V., M. Ranson, and S. M ackem. 1995. The organizerassociated chick homeobox gene Gnot-1 is expressed before gastrulation and regulated synergistically by activin and retinoic acid. Dev. Biol. 171: 458-470.

Kuratani, S., J.F. M artin, S. Wawersik, B. Lilly, G. Eichele, and E.N. Olson. 1994. The expression pattern of the chick homeobox gene gMHox suggests a role in patterning of the limbs and face and in compartimentalization of somites. Dev. Biol. 161: 357-369.

Laufer, E., C.E. N elson, R.L. Johnson, B.A. Morgan, and C. Tabin. 1994. Sonic hedgehog and FGF-4 act through a signaling cascade and feedback loop to integrate growth and patterning of the developing limb bud. Cell 79: 993-1003.

Laverriere, A.C., C. M acN eill, C. M ueller, R.E. Poelmann, J.B.E. Burch, and T. Evans. 1994. GATA-4/5/6, a subfamily of three transcription factors transcribed in developing heart and gut. J. Biol. Chem. 269: 23177-23184.

LeDouarin, N. and C. Bussonnet. 1966. Determination precoce et role inducteur de l'endoderme pharyngien chez l'embryon de poulet. C.R. Acad. Sc. Paris 263D: 1241-1243.

Levin, M., R.L. Johnson, C.D. Stern, M. Kuehn, and C. Tabin. 1995. A molecular pathway determining left-right asymmetry in chick embryogenesis. Cell 82: 803-814.

Levin, M., S. Pagan, D.J. Roberts, J. Cooke, M.R. Kuehn, and C.J. Tabin. 1997. Left/right patterning signals and the independent regulation of different aspects of situs in the chick embryo. Dev. Biol. 189: 57-67.

Liem, K.F., Jr., G. Tremml, M. Roelink, and T.M. Jessell. 1995. Dorsal differentiation of neural plate cells induced by BM Pmediated signals from epidermal ectoderm. Cell 82: 969-979.

Liem, K.F., Jr., G. Tremml, and T.M. Jessell. 1997. A role for the roof plate and its resident TGF $\beta$-related proteins in neuronal patterning in the dorsal spinal cord. Cell 91: 127-138.

Marigo, V., M.P. Scott, R.L. Johnson, L.V. Goodrich, and C.J. Tabin. 1996. Conservation in hedgehog signaling: Induction of a chicken patched homolog by Sonic hedgehog in the developing limb. Development 122: 1225-1232.

Martí, E., D. Bumcrot, R. Takada, and A.P. McMahon. 1995. Requirement of $19 \mathrm{~K}$ form of sonic hedgehog for induction of distinct ventral cell types in CN S explants. Nature 375: 322325.

Masuya, H., T. Sagai, S. Wakana, K. M oriwaki, and T. Shiroishi. 1995. A duplicated zone of polarizing activity in polydactylous mouse mutants. Genes \& Dev. 9: 1645-1653.

Matsushita, S. 1996. Fate mapping study of the endoderm of the 1.5-day-old chick embryo. Roux's Arch. Dev. Biol. 205:225231.

Miralles, F., P. Czernichow, and R. Scharfmann. 1998. Follistatin regulates the rel ative proportions of endocrine versus exocrine tissue during pancreatic development. Development 125: 1017-1024.

Niswander, L., S. Jeffrey, G.R. Martin, and C. Tickle. 1994. A positive feedback loop coordinates growth and patterning in the vertebrate limb. Nature 371: 609-612.
Offield, M.F., T.L. Jetton, P.A. Labosky, M. Ray, R. Stein, M.A. Magnuson, B.L.M. Hogan, and C.V.E. Wright. 1996. PDX-1 is required for pancreatic outgrowth and differentiation of the rostral duodenum. Development 122: 983-995.

Patten, B.M. and B.M. Carlson. 1974. Foundations of embryology (ed. B. Patten and B. Carlson), p. 236. M cGraw-Hill, N ew York, NY.

Pourquié, O., M. Coltey, M.A. Teillet, C. Ordahl, and N.M. LeDouarin. 1993. Control of dorso-ventral patterning of somite derivatives by notochord and floorplate. Proc. Natl. Acad. Sci. 90: 5242-5246.

Riddle, R.D., M. Ensini, C. N elson, T. Tsuchida, T.M. Jessell, and C. Tabin. 1995. Induction of the LIM homeobox gene LmXI by WNT 7a establishes dorsoventral pattern in the vertebrate limb. Cell 83: 631-640.

Riley, B.B., M.P. Savage, B.K. Simandl, B.B. Olwin, and J.F. FalIon. 1993. Retroviral expression of FGF-2 (bFGF) affects patterning in chick limb bud. Development 118: 95-104.

Rosenquist, G.C. 1971. The location of the pregut endoderm in the chick embryo at the primitive streak stage as determined by radioautographic mapping. Dev. Biol. 26: 323-335.

Sander, M., A. N eubüser, J. Kalamaras, H.C. Ee, G.R. Martin, and M.S. German. 1997. Genetic analysis reveals that PAX6 is required for normal transcription of pancreatic hormone genes and islet development. Genes \& Dev. 11: 1662-1673.

Schoenwolf, G.C. and J.L. Smith. 1990. Mechanisms of neuruIation: Traditional viewpoint and recent advances. Development 109: 243-270.

Seleiro, E.A.P., D.J. Connolly, and J. Cooke. 1996. Early developmental expression and experimental axis determination by the chicken Vgl gene. Curr. Biol. 6: 1476-1486.

Shah, S.B., I. Skromne, C.R. Hume, D.S. Kessler, K.J. Lee, C.D. Stern, and J. Dodd. 1997. Misexpression of chick Vgl in the marginal zone induces primitive streak formation. Development 124: 5127-5138.

Sherman, L., K.M. Stocker, R. Morrison, and G. Ciment. 1993. Basic fibroblast growth factor (bFGF) acts intracellularly to cause the transdifferentiation of avian neural crest-derived Schwann cell precursors into melanocytes. Development 118: $1313-1326$.

Slack, J.M.W. 1995. Devel opmental biology of the pancreas. Development 121: 1569-1580.

Sokol, S., G.G. Wong, and D.A. M elton. 1990. A mouse macrophage factor induces head structures and organizes a body axis in Xenopus. Science 249: 561-564.

St.-Onge, L., B. Sosa-Pineda, K. Chowdhurry, A. Mansouri, and P. Gruss. 1997. Pax6 is required for differentiation of glucagon-producing $\alpha$-cells in mouse pancreas. Nature 387: 406409.

Sundin, O. and G. Eichele. 1992. An early marker of axial pattern in the chick embryo and its respecification by retinoic acid. Development 114: 841-852.

Thomsen, G., T. Woolf, M. Whitman, S. Sokol, J. Vaughan, W. Vale, and D.A. M elton. 1990. Activins are expressed early in Xenopus embryogenesis and can induce axial mesoderm and anterior structures. Cell 63: 485-493.

Wessells, N.K. and J.H. Cohen. 1967. Early pancreas organogenesis: Morphogenesis, tissue interactions, and mass effects. Dev. Biol. 15: 237-270.

Wilson, P. and D.A. M elton. 1994. M esodermal patterning by an inducer gradient depends on secondary cell-cell communication. Curr. Biol. 4: 676-686.

Yasuda, H., K. Inoue, H. Shibata, T. Takeuchi, Y. Eto, Y. Hasegawa, N. Sekine, Y. Totsuka, T. Mine, E. Ogata, and I. Kojima. 1993. Existence of activin-A in A- and D-cells of rat pancreatic islets. Endocrinol. 133: 624-630. 


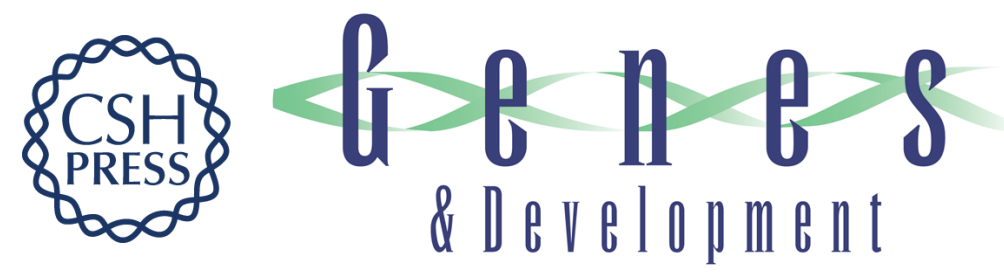

\section{Notochord repression of endodermal Sonic hedgehog permits pancreas development}

Matthias Hebrok, Seung K. Kim and Douglas A. Melton

Genes Dev. 1998, 12:

Access the most recent version at doi:10.1101/gad.12.11.1705

References This article cites 58 articles, 22 of which can be accessed free at: http://genesdev.cshlp.org/content/12/11/1705.full.html\#ref-list-1

License

Email Alerting

Receive free email alerts when new articles cite this article - sign up in the box at the top Service right corner of the article or click here.

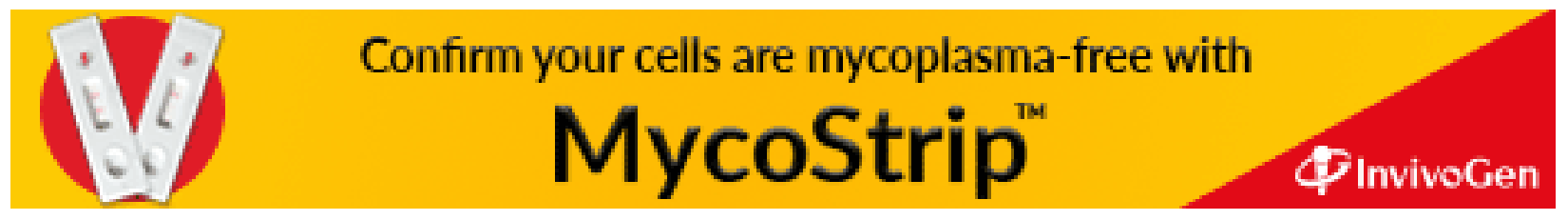

